\title{
Bases del Derecho a la Educación: La Justicia Social y la Democracia
}

\section{Bases of the Right to the Education: The Social Justice and the Democracy}

\author{
Teresa García Gómez *
}

Universidad de Almería, España

Han sido muchos los debates que se han producido y que se siguen produciendo en torno a los derechos humanos, a los que se aluden para denunciar realidades diversas y al mismo tiempo para demandar y justificar acciones y políticas que logren que estos no queden en una mera declaración. El presente artículo es una reflexión sobre el concepto y práctica del derecho a la educación, partiendo de la Declaración Universal de los Derechos Humanos, considerando que este no puede limitarse al derecho a acceder a una institución educativa, sino que este está ligado al concepto de igualdad de oportunidades educativas. Hacer real este principio implica una serie de acciones necesarias en los contextos escolares. Dichas acciones las abordamos a partir de los conceptos de justicia social en educación y escuelas democráticas. Las escuelas democráticas son proyectos colectivos que posibilitan la justicia social al dirigir su acción educativa a las estructuras de opresión, dominación y exclusión, por lo que es necesario que las concreciones que se realicen desde las políticas y administraciones públicas del derecho a la educación lo hagan.

Descriptores: Derecho a la educación; Igualdad de oportunidades; Democratización de la educación; Justicia social; Política educacional.

There have been many debates that have taken place and continue to take place around human rights, which are referred to denounce different realities and at the same time to demand and justify actions and policies that achieve that these are not a mere declaration. The present article is a reflection on the concept and practice of the right to education, based on the Universal Declaration of Human Rights, considering that this cannot be limited to the right to access an educational institution, but it is linked to the concept of equality of educational opportunities. Realizing this principle implies a series of necessary actions in school contexts to ensure this right and principle to the entire population. We address these actions based on the concepts of social justice in education and democratic schools. The democratic schools are collective projects that enable social justice by directing their educational action to the structures of oppression, domination and exclusion, so it is necessary that the concretions made from the public policies and administrations of the right to education do so.

Keywords: Right to education; Equal opportunity; Democratization of education; Social justice; Educational policy.

*Contacto: tgarcia@ual.es

ISSN: 2254-3139

www.rinace.net/riejs/

revistas.uam.es/riejs
Recibido: $\quad 5$ de septiembre 2017

$1^{\text {a }}$ Evaluación: 4 de diciembre 2017

$2^{\text {a }}$ Evaluación: 29 de diciembre 2017

Aceptado: $\quad 5$ de enero 2018 


\section{Introducción}

Han sido muchos los debates que se han producido y que se siguen produciendo en torno a los derechos humanos, a los que se aluden para denunciar realidades diversas y al mismo tiempo para demandar y justificar acciones y políticas que logren que estos no queden en una mera declaración. En el marco de estos debates encontramos las múltiples denuncias del incumplimiento del derecho a la educación, contextualizadas en discursos que abogan por la justicia social como parte fundamental de las sociedades democráticas, que han ido ampliando el desarrollo y el alcance del derecho a la educación. Debates que están más presentes cuando se emprenden las distintas reformas educativas, con el objetivo de llevar a cabo políticas que palien fallas de los sistemas educativos, que se consideran dificultan que el derecho a la educación sea una realidad. Políticas que no han entrado, tampoco han sido forzadas por los debates realizados desde distintos sectores, a plantearse qué se considera por derecho a la educación, más allá de hacer accesible la entrada a la institución educativa, de procurar más medios o recursos al alumnado más desfavorecido socioeconómicamente o a las escuelas situadas en contextos marginales, más allá de emprender acciones para evitar el absentismo y abandono temprano en la institución educativa o, muy presente en los últimos años, más allá de resultados académicos, haciendo el objeto de sus acciones a los sujetos, reflejando que son políticas más centradas en cambiar a los sujetos desfavorecidos que las condiciones estructurales que producen y reproducen las desigualdades y, por tanto, impiden que el derecho a la educación sea una realidad.

Consideremos que el derecho a la educación no puede referirse solo a las medidas que van dirigidas a procurar el acceso a la institución educativa. Es más, estas medidas perderán su fuerza si no se considera que el derecho a la educación engloba también el trabajo realizado en el marco de las instituciones educativas, encaminado a que el proceso educativo sea de calidad, entendiendo por esta los procesos educativos inclusivos que cuestionan la organización escolar y el currículum que se desarrolla, de manera que se posibilita una igualdad real de oportunidades, y no solo formal. Solo esta igualdad real de oportunidades es la que nos va a permitir potenciar la justicia social en educación y el camino para ello es la construcción y desarrollo de escuelas democráticas. Esta es la idea que desarrollamos en este trabajo, definiendo qué entendemos por cada uno de los conceptos mencionados.

\section{El derecho a la educación}

La Declaración Universal de los Derechos Humanos (DUDH) fue aprobada el 10 de diciembre de 1948 por la Asamblea General de las Naciones Unidas en París. Derechos que son inalienables, es decir, engloban un conjunto de derechos fundamentales que las personas tienen por el hecho de existir; asimismo se caracterizan por ser indivisibles, o sea, no se pueden jerarquizar por importancia, todos son importantes, y, además, son interdependientes, por lo que la violación de unos de ellos afectará al no cumplimiento de otro u otros (Kramer, 2010). 
Dos son las Declaraciones que se señalan como antecedentes (Malgesini y Giménez, 2000): la Declaración de la Independencia Norteamericana de 1776, siendo la primera que recoge un catálogo de derechos del hombre y del ciudadano, y como resultado del fin del feudalismo la Declaración de los Derechos del Hombre y Ciudadano de la Revolución Francesa de 1789. A ésta Olympe de Gouges realizó una crítica, reivindicando iguales derechos para las mujeres en una Declaración de los Derechos de la Mujer y la Ciudadana. De ambas Declaraciones se recogen dos ideas básicas presentes en la DUDH: la libertad y la igualdad, cualidades que dan sentido al concepto de dignidad, inherente a todo ser humano sin ningún tipo de limitación, sea económica, sexual, cultural, física, etc. (Jares, 2002).

Una de las características de la Declaración, que la distinguen de los textos que la precedieron, ha sido también la más criticada, concretamente la referida a la universalidad. Distintos colectivos sociales y diferentes Estados mantienen que los derechos humanos que recoge la Declaración no son una construcción universal, sino la imposición de la visión de occidente al resto del mundo (Jares, 2002).

También se ha criticado la supuesta neutralidad, denunciando los rasgos androcéntricos (Jares, 2002), puesto que los derechos se centran básicamente en el llamado espacio público, sin atención a lo que ocurre en el espacio denominado privado. Esta denuncia se traduce en la reclamación de que lo personal también es político, el lema feminista de finales de los años sesenta. Esta crítica logra, en una conferencia mundial sobre Derechos Humanos celebrada en Viena en 1993, que se reconozcan los derechos de las mujeres en ambos ámbitos como parte de los Derechos Humanos.

La Declaración Universal de los Derechos Humanos se ha ido completando con diferentes declaraciones ${ }^{1}$, que no forman parte de esta, pero que dan cuenta del carácter histórico de dicha Declaración, resultantes de los cambios que se han ido produciendo en las relaciones políticas, económicas y culturales, por los que se han ido formulando otros nuevos derechos, y, también, gracias a las luchas y las reivindicaciones sociales de diferentes colectivos y organizaciones. De manera que el articulado de la Declaración se ha ido ampliando con distintos pactos y convenios, por ejemplo, en 1966 la Asamblea General de las Naciones Unidas adopta el Pacto Internacional de Derechos Económicos, Sociales y Culturales $^{2}$ y el Pacto Internacional de Derechos Civiles y Políticos ${ }^{3}$.

Por ello se habla de los derechos de la primera y segunda generación, que son los que recogen la Declaración Universal. Los de la primera generación son los derechos individuales y políticos y los de la segunda generación recoge los derechos sociales, económicos y culturales (Malgesini y Giménez, 2000).

La formulación de nuevos derechos, concretamente en la segunda mitad del siglo xx (Bustamante, 2001), quedan integrados en lo que se ha denominado derechos de la tercera y cuarta generación. La tercera generación, referida a los derechos humanos colectivos, conocida como los derechos de la solidaridad o de los pueblos, y los derechos de la cuarta

\footnotetext{
1 En http://portal.unesco.org/es/ev.php-URL_ID=12027\&URL_DO=DO_TOPIC\&URL_SECTION=-471.html, se puede consultar distintas Declaraciones aprobadas por la Conferencia General de la UNESCO.

${ }^{2}$ Entra en vigor en 1976. Se puede consultar en http://www.ohchr.org/SP/ProfessionalInterest/Pages/CESCR.aspx

${ }^{3}$ Entra en vigor en 1976. Se puede consultar en http://www.ohchr.org/SP/ProfessionalInterest/Pages/CCPR.aspx
} 
generación, son los derechos relativos a la bioética ${ }^{4}$, concernientes a la investigación en el campo de la medicina y de las ciencias de la vida, de la genética (Jares, 2002), y a la revolución tecnológica ${ }^{5}$ que implica la Sociedad del Conocimiento (Graciano, 2013).

La Educación en la DUDH aparece no solo como un derecho en su artículo 26, sino que se vincula también a la intervención educativa en su preámbulo, para promover y asegurar los derechos que en ella se recogen:

\begin{abstract}
1. Toda persona tiene derecho a la educación. La educación debe ser gratuita, al menos en lo concerniente a la instrucción elemental y fundamental. La instrucción elemental será obligatoria. La instrucción técnica y profesional habrá de ser generalizada; el acceso a los estudios superiores será igual para todos, en función de los méritos respectivos.
\end{abstract}

2. La educación tendrá por objeto el pleno desarrollo de la personalidad humana y el fortalecimiento del respeto a los derechos humanos y a las libertades fundamentales; favorecerá la comprensión, la tolerancia y la amistad entre todas las naciones y todos los grupos étnicos o religiosos, y promoverá el desarrollo de las actividades de las Naciones Unidas para el mantenimiento de la paz.

3. Los padres tendrán derecho preferente a escoger el tipo de educación que habrá de darse a sus hijos. ${ }^{6}$ (artículo 26)

La Asamblea General proclama la presente Declaración Universal de Derechos Humanos como ideal común por el que todos los pueblos y naciones deben esforzarse, a fin de que tanto los individuos como las instituciones, inspirándose constantemente en ella, promuevan, mediante la enseñanza y la educación, el respeto a estos derechos y libertades, y aseguren, por medidas progresivas de carácter nacional e internacional, su reconocimiento y aplicación universales y efectivos, tanto entre los pueblos de los Estados Miembros como entre los de los territorios colocados bajo su jurisdicción ${ }^{13}$.

Promover los derechos y las libertades que recogen la Declaración Universal mediante la enseñanza y la educación, sin olvidar que su cumplimiento es básicamente un problema político, implica ligar el proceso educativo, referido tanto al currículum como a la organización escolar, a la igualdad, a la justicia y a la democracia, al desarrollo sostenible y al desarme. Es como señala Gimeno (2005), el derecho a recibir una educación, que incluya en sus contenidos los derechos humanos, acompañado de prácticas educativas en correspondencia con dichos derechos. En nuestro contexto, el derecho a la educación aparece recogido en la Constitución (1978) en su artículo 27.

El derecho a la educación es violado diariamente al igual que el conjunto de derechos que recoge la Declaración, por motivos ideológicos, políticos, económicos, religiosos, etc. No es una realidad para aproximadamente 67 millones de menores en edad de cursar la enseñanza primaria, de los que el $53 \%$ son niñas o para $17 \%$ de las personas adultas del

\footnotetext{
4. Declaración universal sobre Bioética y Derechos Humanos (2005) se puede consultar en http://portal.unesco.org/es/ev.php-URL_ID=31058\&URL_DO=DO_TOPIC\&URL_SECTION=201.html

${ }^{5}$ Robert Gelman, filósofo y psicólogo, en 1997 formuló Los Derechos Humanos del Ciberespacio. En el marco del concepto de "ciudad global", define las bases de la relación entre las personas usuarias, atendiendo a las diferencias en relación a la concentración de información entre los individuos, recogiendo 16 principios necesarios para el uso de la Red, por ejemplo: civilidad, universalidad, voluntariedad, privacidad, libertad, pluralidad y democracia. Dichos principios son la aplicación de pactos sociales para la convivencia (Domingo, 2009, p. 33).

6 Declaración Universal de los Derechos Humanos, consultada en la página de la Naciones Unidas: http://www.un.org/es/documents/udhr/index_print.shtml
} 
mundo, o sea unos 793 millones de personas, de las cuales las dos terceras partes son mujeres, que no tienen las competencias básicas de lectura y escritura ${ }^{7}$.

El derecho a la educación, aparece junto con otros derechos reconocidos a la infancia, en otras declaraciones y convenios, tales como la Declaración de Ginebra (1927), la Declaración de los Derechos del Niño (1959) y la Convención de los Derechos del Niño (1989), reconociendo a la infancia, además, por ejemplo, el derecho a participar plenamente en la vida cultural, artística, etc.; a la libertad de expresión, de información y de pensamiento; libertad de asociación, etc. Derechos que son alterados también, en parte, por la visión reduccionista que de forma generalizada se tiene de la infancia, limitando su espacio y restringiendo sus posibilidades y capacidades, llevando a las personas adultas a pensar, decidir, hacer, etc. por ella.

A nuestro modo de ver, las acciones emprendidas para lograr que el derecho a la educación sea una realidad han reducido la educación a la escolarización, entendiéndola, al mismo tiempo, como instrucción, que bloquean desde nuestro punto de vista la justicia social en educación y la democracia en los centros educativos, lo que imposibilita una igualdad real de oportunidades.

Instrucción y educación no son sinónimos. La instrucción hace referencia a los procesos de enseñanza-aprendizaje, que se desarrollan en el contexto del aula, con el objetivo de que el profesorado transmita unos conocimientos al alumnado en un marco de socialización para que este los adquiera. Sin embargo, la educación incorpora dos elementos substanciales según Torres Santomé (2011): la crítica, que nos permite conocer y analizar rigurosamente la realidad, y la ética, el compromiso a través de nuestras acciones con unos valores en correspondencia con la justicia y la igualdad. En este sentido, Santos Guerra (2000) señala que estaban muy instruidos, formados en su oficio los médicos, las enfermeras y los ingenieros que diseñaron las cámaras de gas en la II Guerra Mundial o la bomba atómica, pero esta formación no es educación. En palabras de Torres Santomé (2011),

\begin{abstract}
educar es preparar a niñas y niños y adolescentes para llegar a ser personas autónomas, capaces de tomar decisiones y elaborar juicios razonados y razonables, tanto sobre su conducta como sobre la de las demás personas; de dialogar y cooperar en la resolución de problemas y en propuestas de solución encaminadas a construir una sociedad más justa. Para este objetivo, toda persona educada necesita disponer de contenidos culturales relevantes, que le permitan comprender el mundo $y$, simultáneamente, desarrollar sus capacidades cognitivas, afectivas y sociales con las que poder sacar el mejor partido a sus derechos y deberes como ciudadano y ciudadana. (p. 206)
\end{abstract}

Además, la instrucción hace referencia a un tiempo acotado, es decir, el tiempo en el que una persona asiste a una institución, en nuestro caso a la escuela referida a la etapa de escolarización; sin embargo, la educación es un proceso que dura toda la vida. Estas diferencias, grosso modo, se aprecian si comparamos el artículo 26, el derecho a la educación, de la Declaración Universal de los Derechos Humanos, y el capítulo quinto de la educación y el conocimiento de La Carta de los Comunes (2011). En el artículo 26 la educación, en gran parte, es reducida a escolarización, considerando sólo la etapa obligatoria como gratuita, a la vez que refleja una visión meritocrática de la instrucción, serán los méritos-

7 Datos extraídos del Informe 2011, La UNESCO $\quad$ y $\quad$ la educación. Recuperado de
http://unesdoc.unesco.org/images/0021/002 127/212715s.pdf 
resultados escolares de los individuos los que darán la posibilidad de seguir cursando las enseñanzas no obligatorias, por lo que esta etapa educativa tendrá -y tiene- una función selectiva. Es decir, es el individuo el único responsable de sus méritos, obviando los condicionamientos sociales, los que tenía Baktay, la protagonista de la película Buda explotó por vergüenza ${ }^{8}$, quien realiza una lucha continua para ir a la escuela enfrentándose a la ideología patriarcal, a las políticas educativas, a la falta de recursos, a la indiferencia de las personas adultas, a la actitud y despreocupación de maestros y maestras, etc. Mientras que en La Carta de los Comunes la educación es el proceso que dura toda la vida y es considerada un bien común, de todos y de nadie al mismo tiempo, que no puede ser negada a ningún individuo, todos han de beneficiarse de ella, puesto que se considera junto con el conocimiento, una de las mayores riquezas comunales, por lo que es responsabilidad de todas las personas mantenerla y mejorarla, porque de ella depende la vida en común, sin separaciones ni exclusiones, sin conciertos, y con centros abiertos todo el día.

Por tanto, entendemos la escolarización como parte del derecho a la educación, y esta como un bien común. Es decir, la escolarización -práctica en la que se ha concretado la idea de educación en la DUDH- es, según Carbonell (2008, p. 32) "una condición necesaria, pero no es suficiente para asegurar el derecho a la educación". Para el cumplimiento de este es necesario la igualdad de oportunidades educativas, entendida tanto como la igualdad formal, que asegura la escolarización, el acceso a la escuela, procurada en los llamados países desarrollados a través de la legislación y políticas educativas, como la igualdad real, referida al proceso educativo, lo que Carbonell (2008) denomina las condiciones de la escolarización, que este sea de calidad, lo que implica un educación comprensiva e inclusiva, al alcance de todos y de todas, común -sin itinerarios-, útil y que potencie el aprender a aprender. Una educación de calidad es, por tanto, aquella que posibilita a las personas no limitar su potencia (Spinoza, citado por Lukes, 2007), desarrollar su autonomía, la perspectiva crítica, la independencia intelectual, la creatividad, la solidaridad y la colectividad, la compresión de sí mismas y del mundo que habitan para transformarlo y mejorarlo, y ser libres.

En todos los países existen múltiples formas de alterar el derecho a la educación, en lo que se refiere al acceso a esta y al proceso. Así, el acceso a la educación se ve obstaculizado por las prácticas patriarcales -negación de la educación a las mujeres, matrimonios de edades muy jóvenes, embarazos prematuros, etc.-, los conflictos armados, el trabajo infantil, la explotación sexual, la pertenencia a clases sociales bajas o etnias minoritarias que condiciona el fracaso escolar', la falta de infraestructuras, las políticas neoliberales que reducen la intervención del Estado en materia educativa, reduciendo los gastos en la enseñanza pública con una mayor financiación a la enseñanza privada, etc. De igual manera, las condiciones de escolarización obstaculizan el proceso educativo, viéndose afectada la calidad de este por los objetivos educativos; los contenidos seleccionados; las metodologías desarrolladas; los recursos empleados; la organización del tiempo y del espacio escolar; la formación del profesorado y las expectativas que este tiene respecto al alumnado; el código lingüístico (Bernstein, 1990) que utiliza la escuela para la transmisión

\footnotetext{
${ }^{8}$ Dirigida por Hana Makhmalbaf en 2007.

${ }^{9} \mathrm{El}$ origen social condiciona el fracaso escolar (Carbonell, 2008), que referido al derecho a la educación en cuanto a acceso implica abandono o el impedimento de continuar niveles educativos más elevados. Nos sirve de ejemplo los datos del estudio de Fernández Enguita, Mena y Riviére (2010), que pone de manifiesto que el riesgo de fracaso escolar en el alumnado de clase trabajadora es del $45 \%$ frente al $23 \%$ de la clase media; y el caso del alumnado migrante, el riesgo es del $55 \%$ y del $41 \%$ si es alumnado migrante de segunda generación frente al $34 \%$ del alumnado español.
} 
del conocimiento; la relación que esta mantiene con las familias-comunidad-entorno; el capital cultural de las familias (Bourdieu, 2000); los procedimientos de evaluación; el fracaso escolar ${ }^{10}$; las insuficientes políticas compensatorias; la brecha digital; las políticas educativas neoliberales que enfatizan los resultados, supeditando los procesos, o la consideración de la libertad de elección de centros por parte de las familias -la libre elección de la educación por parte de estas está recogida también en el artículo 26 de la DUDH-, en su idea de que la educación es un gran mercado (Contreras, 1997; Apple, 2002; Torres Santomé, 2011) y la libre elección dejará fuera de este a los "malos" centros, desapareciendo estos, y quedando los "buenos" centros para ser elegidos. Son varias las objeciones a esta creencia y afirmación, en lo que se refiere a la igualdad de oportunidades, puesto que el capital cultural de la familias influye en la posible elección, no todas tienen la misma información, no es cierto que los considerados "malos centros" desaparecerán, sino que quedarán destinados para poblaciones concretas -las más desfavorecidas-, y no está tan claro que sean las familias las que realmente elijan los centros a los que asistirán sus hijos e hijas, sino más bien al contrario, son los centros los que eligen a su alumnado porque de ello dependerá obtener buenos resultados que les procurarán mayores subvenciones y más reconocimiento y prestigio social.

Por tanto, atendiendo a los dos ámbitos a los que se refiere la igualdad de oportunidades educativas -acceso y proceso- para hacer efectivo el derecho a la educación, dos serán los ámbitos de acción: la luchas y reivindicaciones sociales y educativas para lograr la educación como un bien común, y, en conexión con esta, la acción educativa -tanto en su contenido como en su práctica- en el marco de las escuelas en conexión con sus comunidades, es la intervención de los maestros y de las maestras como agentes de cambio, como intelectuales críticos transformadores (Giroux, 1990; Kincheloe, 2008), convirtiendo los procesos instructivos en procesos educativos democráticos, que favorecerán la justicia social.

\section{Justicia social en educación}

El acceso a la escolarización es una cuestión directamente relacionada con la justicia distributiva, entendiendo por esta el reparto igualitario y equitativo de bienes materiales e inmateriales -educación, trabajo, vivienda, amor, tiempo libre, etc.-. Las acciones para la justicia distributiva en educación se han centrado básicamente en conseguir una mayor distribución del bien educativo, entendido como acceso a la institución escolar y a los títulos formales (Connell, 1997, p. 25), puesto que existe una distribución desigual, no beneficiándose todas las personas por igual, por lo que no se ha entendido la educación vinculada a los bienes comunes ni se ha contemplado los elementos que la distinguen de la instrucción: la ética y la crítica, como hemos señalado anteriormente.

Actualmente, como señala Connell (1997), el sistema educativo es un bien público, gracias a las reivindicaciones y luchas de movimientos y colectivos sociales para que dejara de ser privado, al que los Estados destinan parte de sus presupuestos, por lo que sería un bien del conjunto de la ciudadanía y esta debería beneficiarse por igual. Sin embargo, la institución educativa muestra una estructura piramidal, que deja patente la desigual ${ }^{10}$ Entendido durante el proceso educativo cuando el alumnado no le encuentra sentido a lo que tiene que aprender, cuando
se aburre, cuando promociona, aunque "no haya aprendido", etc. 
distribución de los recursos que conforman la educación formal, y, por tanto, de sus beneficios, puesto que la posesión o no de capital cultural institucionalizado (Bourdieu, 2000) repercutirá posteriormente en el acceso al mercado laboral y a la oferta de este. Por ello Connell (1997) afirma que "el sistema educativo, por tanto, no solo distribuye los bienes sociales actuales. También conforma el tipo de sociedad que está naciendo, que nuestra sociedad futura sea justa depende, en parte, del uso que hagamos del sistema educativo" (p. 22).

Las personas beneficiarias en los países llamados desarrollados van disminuyendo en la medida que se va elevando el nivel educativo, concretamente son las personas pertenecientes a clases sociales bajas, etnias minoritarias, etc. las que acceden en menor medida a los niveles superiores, por lo que la procedencia social genera oportunidades desiguales para beneficiarse de los distintos tramos educativos (Connell, 1997; Fernández Enguita, Mena y Riviére, 2010). Situación que se agrava en los países llamados en vía de desarrollo, en los que el problema está en hacer llegar a toda la población la enseñanza primaria. Refiriéndose a esta situación de injusticia distributiva a escala mundial en lo que a educación se refiere, Connell (1997) señala "la existencia de una pirámide de pirámides" (p. 19).

Distintas han sido las medidas adoptadas para lograr una mayor justicia distributiva. En los países llamados desarrollados, en primer lugar, se procuró el acceso a toda la población a la enseñanza primaria, posteriormente se aplican una serie de políticas de igualdad de oportunidades para asegurar el acceso a los niveles superiores y más selectivos -enseñanza secundaria posobligatoria y universitaria-. De ahí, los programas de educación compensatoria, becas, programas de promoción de las mujeres, etc.; y las campañas de alfabetización en los llamados países en vía de desarrollo para ampliar la base de la pirámide y hacer que la educación primaria llegue a toda la población.

Todas estas medidas para hacer posible una distribución justa del bien educativo ponen el énfasis en la cantidad y no en la calidad, es decir, no se cuestiona qué tipo de educación se imparte ni cómo se desarrolla. Por ello Connell (1997) señala que cuánta educación no se puede separar de qué educación, a la vista de los resultados de las investigaciones en el marco de la sociología de la educación que señalan que existe una relación directa, como ya hemos apuntado, entre contenidos que imparte la escuela y desigualdades sociales, por lo que produce y reproduce las jerarquías socioculturales, legitimando las desigualdades, puesto que lleva a pensar que las diferencias son cuestiones individuales, considerando que las personas que resultan más beneficiadas en la distribución es debido a su esfuerzo, interés e inteligencia.

Por ello el autor afirma que "la justicia distributiva es una forma incompleta de entender las cuestiones educativas" (Connell, 1997, p. 29), señalando que esta debe ir acompañada de justicia curricular. En esta línea, desde nuestro punto de vista, sin el desarrollo de justicia curricular, que es posible lograrla a través de la construcción de escuelas democráticas, la justicia distributiva no se logrará.

La justicia curricular implica reconstruir el currículum socialmente dominante o hegemónico, en cuya selección de contenidos y en la forma de abordarlos está la visión, los intereses y los objetivos del grupo dominante, que Moreno (1986) denomina el arquetipo viril -occidentales, varones, blancos, clase media-. Sírvanos de ejemplo de dichos intereses y visión del mundo la proyección de este que realiza Mercator (1589) a la 
que se contrapone la realizada por James Gall (1856) y Peters (1974)11, en la que se evidencia la visión eurocentrista del mundo, propia del colonialismo, aumentando el tamaño de los continentes del Norte y disminuyendo el llamado Tercer Mundo.

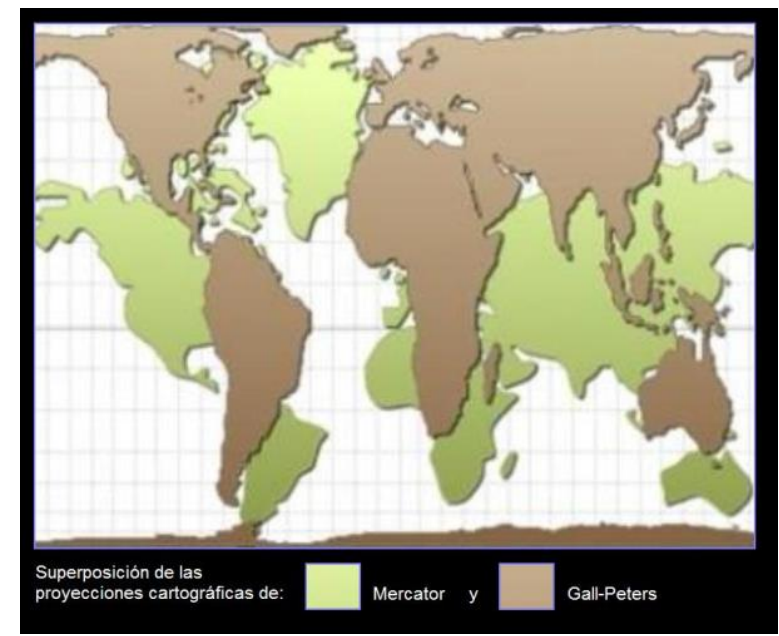

Figura 1. Comparativa de la proyección cartográfica de Mercator y Gall-Peters Fuente: http://soldeloslatinos.blogspot.com.es/2012/01/falsos-y-verdaderos-mundos-segunlos.html

El currículum hegemónico excluye, por tanto, otros conocimientos y formas de producirlos y organizarlos, otras experiencias, es la exclusión de otros colectivos minoritarios o sin poder -mujeres, clases sociales bajas, otras culturas, etc.- y que, en definitiva, favorece a la reproducción de dicha exclusión. La reconstrucción de dicho currículum, el de la corriente principal, implica desarrollar un currículum contrahegemónico (Connell, 1997), incorporando las perspectivas, intereses, necesidades y experiencias de los grupos más desfavorecidos -maginados y sin poder-, indagando en las distintas cuestiones desde la marginalidad. Dicha incorporación supone el reconocimiento de los otros colectivos y el enriquecimiento del perteneciente al grupo dominante, ya que obtendrá un conocimiento más fiel y cercano a la realidad. Asimismo, este nuevo currículum común, diverso y multicultural debe posibilitar la participación de todos y todas, sin ninguna distinción, en la toma de decisiones en las cuestiones que afectan a la escuela (Connell, 1997, 2008; Torres Santomé, 2011).

En este marco de la justicia curricular podemos situar la justicia cognitiva, que señala Félix Angulo (2016), refiriéndose a la coexistencia de diversas formas de conocimiento, reconociendo tanto la diversidad de conocimientos como la igualdad de los sujetoscolectivos conocedores para promover un "conocimiento poderoso" (Young, 2014 citada por Angulo 2016, p. 39) -también lo que denominamos saberes útiles-, que permita comprender y explicar el mundo en el que vivimos; así como anticipar, idear y promover alternativas radicalmente democráticas, ya que las prácticas curriculares contrahegemónicas tienen como objetivo desarrollar y ampliar la capacidad de las personas para comprender y mejorar su mundo. ${ }^{11}$ Proyección de Gall-Peters es la denominación correcta, ya que la proyección cartográfica que presenta Peters se
corresponde con la elaboradora por el religioso escocés James Gall. 
Por último, en relación a la justicia curricular, para hacerla posible, es necesaria la justicia relacional, referida a la calidad de las relaciones, exentas de opresión, dominación y exclusión (Young y Fraser citadas por Connell, 2008, p. 61), denominada por Angulo (2016) justicia afectiva, en relación al desarrollo del vínculo con los Otros, al cuidado hacia los demás, a la ocupación y preocupación por el bienestar de las demás, que en definitiva es el cuidado del ser-mundo.

\section{Construcción y desarrollo de escuelas democráticas}

La justica en educación -distributiva, curricular y relacional- requiere de la democracia, es decir, de la democratización de este bien y de una organización democrática, entendiendo que la democracia, como señala (Dewey, 1998), "es más que una forma de gobierno; es primeramente un modo de vivir asociado, de experiencia comunicada conjuntamente" (p. 82). Entendemos por democracia la organización política, económica y social, que manteniendo el respeto a los Derechos Humanos, posibilita la "asociación general de los hombres que poseen colegiadamente el supremo derecho a todo lo que puede [la sociedad]” (Spinoza, 1986, p. 338), considerando el poder como potencia, es decir, la capacidad para producir cualquier cambio o resistirse a él (Lukes, 2007), y también como el poder con..., y el ejercicio democrático no limitaría la potencia de las personas en cuanto a poder y capacidad para actuar, incidir y afectar.

Por tanto, cuando hablamos de escuelas democráticas, no lo hacemos en el sentido de democracia representativa, en el que las personas delegan en otras para la toma de decisiones, que está limitada, ya que no se refiere a todos los asuntos de carácter común; sino de democracia participativa, en la que todas las personas, independientemente de la posición que tengan en la institución, intervienen en la toma de decisiones en las cuestiones de relevancia que afectan a la vida de las escuelas con el propósito de poner en práctica una educación liberadora (Freire, 1992) y posibilitar que los alumnos y las alumnas se conviertan en ciudadanas del mundo (Domínguez, 2010, p. 1), críticas, libres, iguales, justas y solidarias, desarrollando todas las dimensiones relevantes de la ciudadanía: ética, cívica, económica, ecológica, intercultural y política. En este marco podrán ser ciudadanos y ciudadanas demócratas y democratizadoras (Domínguez, 2010).

El desarrollo de la democracia participativa y crítica en las escuelas se materializa en su gestión y organización -tanto del centro como del aula-, en su currículum y en la acción del profesorado. Las características de las escuelas democráticas, atendiendo a las aportaciones de distintos autores y autoras (Apple y Beane, 1997; Beane, 2005; Carbonell, 2001, 2015; Feito, 2006; Feito y López, 2008; García Gómez, 2004, 2011; Guerra, 1995; Guarro, 2002a, 2005; Santos Torres, 2011; Pérez Gómez, 2012; entre otros) y a las investigaciones que hemos realizados sobre distintas escuelas ${ }^{12}$, que definen cada uno de los ámbitos de acción serían las siguientes:

a) Organización escolar

1. Proyectos educativos contrahegemónicos, oponiéndose a los valores imperantes de del modelo actual de educación, y a los sociales en general, regidos por la economía de mercado propia del sistema capitalista o de otros sistemas de explotación y dominación

12 Escuela Libre de Paideia, CEIP Trabenco, Ambiente de Aprendizaje Ojo de Agua, O Pelouro, Escuela Popular de Prosperidad, Escuelas Zapatistas, Bachilleratos Populares, etc. 
como el patriarcal (García Gómez, 2004, 2011). La democracia se imposibilita con la exclusión, invisibilidad y marginalidad de parte de la humanidad. Miyares (2003) refiriéndose a las mujeres señala que sin estas no hay democracia, afirmación que extendemos a todos los colectivos excluidos y dominados. Son, en definitiva, un aspecto más en la búsqueda de una sociedad diferente, forman parte de un proyecto más global: construir-reclamar otro mundo, vivir otra vida.

2. Proyectos pensados y puestos en práctica desde la base -profesorado, padres-madres, alumnado-, y no elaborados por especialistas, al margen de los contextos escolares, para que sean desarrollados por el profesorado. La transformación se produce de abajo arriba (Apple y Beane, 1997).

3. La teoría y la práctica van de la mano, ambas se alimentan mutuamente, existiendo una relación dialéctica entre ellas, se convierten en una misma cosa. Es praxis, en que "la acción y la reflexión, solidarias, se iluminan constantemente y mutuamente. En la cual, la práctica, implicando la teoría, de la cual no se separa, implica también una postura de quien busca el saber, y no de quien, pasivamente lo recibe" (Freire, 1975b, p. 92). Es a través de la praxis como se puede lograr la concientización (Freire, 1975a), es decir, un proyecto colectivo para lograr el conocimiento crítico, comprensión crítica y transformación crítica de la realidad, en este caso de la realidad educativa objeto de transformación.

4. Están sustentadas en valores democráticos: participación, inclusión, solidaridad, libertad, igualdad -de acceso, éxito y utilidad-, respeto, ayuda, cooperación, compromiso, responsabilidad y corresponsabilidad, etc. (Feito y López, 2008; García Gómez, 2004, 2011); y de justicia social, tanto distributiva como relacional (Connell, 1997, 2008), por lo que las escuelas trabajan para eliminar las barreras institucionales (Apple y Beane, 1997), atentas a las condiciones que las crean dentro y fuera de estas.

5. Toda la comunidad educativa interviene en la toma de decisiones en los aspectos que conciernen al trabajo diario de la escuela y del aula, sin ningún tipo de limitación como puede ser la edad, mediante asambleas y procesos de negociación -caracterizados por el diálogo y la transparencia-, buscando compaginar los intereses individuales y los colectivos, para lograr acuerdos que favorezcan el bien común (intereses, expectativas y deseos de todas las personas), y no marginando así opiniones o propuestas minoritarias cuando el procedimiento es el voto y se realiza una "gestión del consentimiento" (Apple y Beane, 1997, p. 25). Es el derecho de toda comunidad escolar de participar en el proceso de toma de decisiones partiendo de su realidad concreta, el derecho de las personas a ser participantes de, y en, una comunidad de aprendizaje, que por su naturaleza será diversa (Apple y Beane, 1997). Hacer posible el derecho a participar requiere que toda la información circule por diferentes vías para que llegue a todos los sectores de la comunidad educativa. Aspecto de vital importancia para que todas las personas puedan implicarse activamente en la toma de decisiones, para una participación informada (Santos Guerra, 2003, 2013).

6. La cooperación y la colaboración definen el trabajo de la escuela. Todas las personas implicadas en los procesos de enseñanza-aprendizaje tienen responsabilidades en estos y asumen las consecuencias de sus acciones (García Gómez, 2004, 2011). La democracia es compromiso y corresponsabilidad.

7. La diversidad es un valor. No pretenden y rechazan la homogeneización del alumnado, respetando los ritmos y el desarrollo individual, considerando las diferencias individuales 
y la diversidad como una fuente de riqueza y aprendizaje (Apple y Beane, 1997), y no como un problema o una fuente de desigualdad, jerarquización y segregación.

8. Los agrupamientos son diversos y flexibles. El criterio de agrupamiento del alumnado no es la edad -algo totalmente artificial creado por la escuela-, sino los intereses, necesidades y deseos, favoreciendo así las relaciones inter e intrageneracionales, y enriqueciendo los procesos socializadores y de aprendizaje.

9. El aprendizaje no se limita a un espacio y a un tiempo concreto y determinado. Es decir, cualquier espacio y cualquier momento del día son aprovechados para potenciar y favorecer el aprendizaje. El espacio y tiempo son educativos, están en función de las finalidades educativas, del aprendizaje y de las personas -ritmos, necesidades, etc.-, de los aprendizajes que se quieren provocar. Se busca la calidad del tiempo, atento a los procesos, a los acontecimientos y a las personas (Domènech, 2011)

10. Se utilizan diversos y variados recursos -materiales y digitales- para acceder a informaciones múltiples y diversas que posteriormente serán contrastadas. No se utiliza, por tanto, con exclusividad ni como fuente principal de información el libro de texto, el cual suele proporcionar una información sesgada y reduccionista, y favorece a la empresa editorial, además de reproducir y ayudar a mantener las posiciones dominantes. Asimismo, aprovecha el capital cultural de la comunidad y el entorno forma parte de los recursos educativos.

11. Todas las personas (docentes, alumnado, madres-padres, otros miembros de la comunidad) poseen saberes y habilidades diversas que son compartidas y enseñadas. El aprendizaje no es unidireccional -el alumnado aprende de lo que es transmitido o enseñado por el profesorado-, sino que todos los sujetos aprenden de todos, el aprendizaje es multidireccional. Todas las personas son aprendices y enseñantes "en la situación educativa, educador y educando asumen el papel de sujetos cognoscentes, mediatizados por el objeto cognoscible que busca conocer" (Freire, 1975b, p. 28).

\section{b) Currículum democrático}

12. El objetivo es una educación para la emancipación de los sujetos, que permita conocer su realidad para transformarla -de lo local a lo global-, formar una ciudadanía crítica, activa y justa. Así como el desarrollo de las potencialidades del alumnado, posibilitándole también su ampliación.

13. Todos los contenidos son importantes, no solamente el conocimiento oficial. No hay una jerarquización del conocimiento, ni este se adquiere de forma parcializada sino de forma integral (afectivo, intelectual, manual, social, corporal...). Se valoran y se reconocen las distintas culturas, no solo la académica, así como sus diferentes formas de expresión (Torres Santomé, 1994). Asimismo, incorpora los intereses, preocupaciones, las cuestiones del alumnado.

14. El conocimiento no es algo para ser acumulado, sino que tiene un valor de uso, sirve de base para conocer las relaciones y mecanismos sociales que generan dominación y opresión, así como para conocer la realidad más inmediata y poder actuar sobre ella. Por tanto, el currículum sensibilizaría y concienciaría sobre el clasismo, sexismo, racismo, etnocentrismo, la destrucción medio ambiental, los sistemas de explotación, etc. que limitan la construcción y el desarrollo de la democracia. Sería un instrumento para estudiar alternativas, que al mismo tiempo formen en una ciudadanía crítica, activa y 
creativa. En este sentido, el currículum tendría que desarrollarse en torno a cuatro ejes (Guarro, 2002a, 2002b, 2005; Bolívar, 2002): socioeconómico -orientado por la justicia, el desarrollo sostenible, el consumo responsable, etc.-, sociopolítico -guiado por la democracia participativa, al autogestión, el desarme, los derechos humanos-, sociocultural -orientado por la igualdad y la equidad, la reducción de la brecha digital, etc.- y sociopersonal -la autonomía, la responsabilidad, la salud personal y colectiva, la educación afectivo-sexual-. Estos ámbitos permiten abordar las grandes problemáticas planteadas. Se considera el conocimiento como un instrumento para conseguir la igualdad y humanizar la vida, está al servicio del ser humano.

15. El conocimiento se trabaja de forma globalizada e interdisciplinar desde una perspectiva crítica, incorporando lo no dicho, lo ausente (las culturas de grupos oprimidos y excluidos como las mujeres, la clase obrera...), como resultante de las relaciones de poder y dominación, y desde una perspectiva "conexionista" que sitúa "en el centro del proceso educativo la conexión de uno con la vida de todos los seres humanos, y demás seres vivos de nuestro planeta. [...] enfatiza los vínculos y las responsabilidades sociales" (Goodman, 2008, p. 133). En definitiva, un currículum contrahegemónico, incorporando a la corriente principal los intereses, las experiencias y los puntos de vista de los grupos excluidos (Connell, 1997).

16. Las metodologías empleadas en los procesos de enseñanza-aprendizaje son participativas, las cuales favorecen la investigación, el aprendizaje por descubrimiento, aprender a aprender y la construcción de una cultura colaborativa (Guarro, 2002a); empleando, como diría Freire y Faundez (2010), la pedagogía de la pregunta como método de cuestionar al conocimiento y desvelar sesgos, ocultaciones, reduccionismos, intereses, etc. en la producción y selección del mismo del mismo. Por tanto, el alumnado no mantiene un papel pasivo en el proceso de aprendizaje, no es un mero receptor y consumidor de conocimientos, sino que mantiene una postura activa cuestionando y reflexionando, en definitiva, reconstruyendo el conocimiento para aprender de forma significativa y relevante. Es decir, el alumnado tiene un papel de intérprete crítico ante el conocimiento -quién, cómo, por qué, para qué- (Apple y Beane, 1997, p. 31), visibilizando el currículum oculto e incorporando voces ausentes.

17. La evaluación es formativa y continua para reorientar el proceso de enseñanzaaprendizaje y potenciar este, y nunca para jerarquizar, etiquetar, segregar o limitar, es transparente, al servicio de los sujetos que aprenden, contextualizada, holística y está integrada en el currículum (Álvarez Méndez, 2001, Santos Guerra, 2000). Atenta a los distintos aprendizajes -conceptuales, procedimentales y actitudinales-, tanto individuales como grupales (Guarro, 2002a). Al mismo tiempo, se realizan prácticas de autoevaluación y coevaluación (García Gómez, 2004, 2011), en las que participan diferentes miembros de la comunidad educativa.

\section{c) Papel del profesorado}

18. El profesorado no es un transmisor del conocimiento, sino un facilitador de las condiciones de aprendizaje para que el alumnado esté motivado, interesado en adquirir nuevos saberes.

19. El profesorado no es un técnico que aplica las últimas reformas planteadas o aprobadas, sino que él mismo controla su trabajo y el currículum que se desarrolla (Apple y Beane, 
1997), cuestionando y reflexionando permanentemente sobre su práctica para encauzarla y mejorarla, emprendiendo procesos de investigación acción participativa y crítica.

20. El profesorado es agente de cambio educativo y social, que entiende y asume la naturaleza política de la educación (Freire, 1990).

21. Se constituye en comunidades críticas de aprendizaje (Imbernón, 2013) como espacios de formación colaborativa y de acción colectiva.

22. La pedagogía de cuidado mutuo caracteriza la relación que mantiene con el alumnado y con la comunidad educativa, traducida en acciones cotidianas de afecto, tacto, atención, sensibilidad, comprensión, escucha, mimo, consideración, etc. Acciones cotidianas que harán de la escuela un lugar común y de seducción por el saber y la vivencia del conocimiento como algo placentero (Rogero, 2010).

Construir y desarrollar escuelas democráticas, como señalan Apple y Beane (1997), requiere de unas condiciones previas: la libre circulación de ideas; el análisis reflexivo crítico de las situaciones, problemas, propuestas y políticas; la pre-ocupación por el bienestar de los Otros y el bien común; el respeto de los derechos de los individuos y de los colectivos; la organización institucional, conectada con otras instituciones, promueva y amplíe la forma de vida democrática, no como ideal sino como vivencia en nuestra cotidianidad. En definitiva, una escuela democrática es el aprendizaje mismo de la democracia experimentándola.

\section{Conclusiones}

Hacer real el derecho a la educación implica hacer transformaciones radicales desde las propias escuelas, transformar estas en escuelas democráticas, las cuales crean un espacio público, perteneciente a todos y a todas, por lo que las decisiones sobre asuntos comunes dejan de tomarse privadamente y son tomadas en comunidad, abierta a la participación de todas, y de un tiempo público. Un espacio de producción cultural, de construcción de una cultura democrática que dará oportunidades a sus participantes para resolver tanto problemas prácticos como morales/éticos y sociales por medio del cuestionamiento reflexivo, de la deliberación colectiva, las actividades conjuntas y las decisiones colectivas, formando parte de dicha cultura la práctica de la educación para la emancipación, para liberación de las estructuras opresoras y dominadoras, para ser más, para la humanización. Por tanto, forma parte de la educación democrática el proceso de concientización, que permitirá desarrollar una conciencia crítica, una comprensión crítica de la realidad, que posibilitará que las personas se integren en sus contextos -no que se adapten-, entender su posición en estos y las causas de los hechos y de los problemas. La concientización ni es un acto puramente intelectual ni individual, es un proceso social que tiene lugar en las relaciones de transformación de la realidad, con el mundo, y solo es posible en la praxis concreta. Es decir, como praxis política al servicio de la permanente liberación de los seres humanos, que no se da solo en sus conciencias, sino en la radical transformación de las estructuras, en cuyo proceso se transforman las conciencias (Freire, 1975c).

Por tanto, forma parte del proyecto de educación democrática la justicia social, entendiendo que las personas no son las responsables de la condición desigual, sino que es resultado de una injusticia estructural, y las escuelas democráticas, a través de los procesos de concientización, van dirigidas a reformar las estructuras y cambiar las relaciones. En definitiva, las escuelas democráticas son proyectos colectivos que posibilitan la justicia 
social al dirigir su acción educativa a las estructuras de opresión, dominación y exclusión, por lo que es necesario que las concreciones que se realicen desde las políticas y administraciones públicas del derecho a la educación lo hagan, en otros términos, posibilitando y favoreciendo la construcción de dichos proyectos.

\section{Referencias}

Álvarez Méndez, J. M. (2001). Evaluar para conocer, examinar para excluir. Madrid: Morata.

Angulo, F. (2016). Las justicias de la escuela pública. Revista Interuniversitaria de Formación del Profesorado, 30(1), 37-47.

Apple, M. (2002). Educar como dios manda. Barcelona: Paidós.

Apple, M. y Beane, J. (Comps.). (1997). Escuelas democráticas. Madrid: Morata.

Beane, J. (2005). La integración del currículum. Madrid: Morata.

Bernstein, B. (1990). Códigos. En B. Bernstein, Poder, educación y conciencia (pp. 47-66). Barcelona: El Roure.

Bolívar, A. (2002). Nuestra propuesta de educación democrática. Cuadernos de Pedagogía, 317, 5356.

Bourdieu, P. (2000). Las formas del capital. Capital económico, capital cultural y capital social. En P. Bourdieu, Poder, derecho y clases sociales (pp. 131-164). Bilbao: Deseleé de Brouwer.

Bustamante, J. (2001). Hacia la cuarta generación de derechos humanos: Repensando la condición humana en la sociedad tecnológica. Recuperado de http://www.oei.es/historico/revistactsi/numero1/bustamante.htm

Carbonell, J. (2001). La aventura de innovar. Madrid: Morata.

Carbonell, J. (2008). Derecho a la educación e igualdad de oportunidades. En J. Carbonell, Una educación para mañana (pp. 29-44). Barcelona: Octaedro.

Carbonell, J. (2015). Pedagogías del siglo XXI. Barcelona: Octaedro.

Connell, R. W. (1997). Escuelas y justicia social. Madrid: Morata.

Connell, R. W. (2008). Escuelas, mercado, justicia: La educación en un mundo fracturado. En F. Angulo (Ed.), Educación, justicia y democracia en las instituciones educativas (pp. 49-67). Sevilla: Cooperación Educativa.

Contreras, J. (1997). La autonomía del profesorado. Madrid: Morata.

Dewey, J. (1998). Democracia y educación. Madrid: Morata.

Domènech, J. (2011). Elogio de la educación lenta. Barcelona: Graó

Domingo, V. (2009). Los derechos humanos de cuarta generación. Crítica, 59(959), 32-37.

Domínguez, J. (2010). Democracia, educación y escuela. Recuperado de http://accioneducativamrp.org/wp-content/uploads/2014/04/DemocraciaEducacionEscuela.pdf

Feito, R. (2006). Otra escuela es posible. Madrid: Siglo XXI.

Feito, R. y López, J. I. (2008). Construyendo escuelas democráticas. Barcelona: Hipatia.

Fernández Enguita, M. Mena, L. y Riviere, J. (2010). Fracaso y abandono escolar en España. Madrid: Fundación la Caixa.

Freire, P. (1975a). Acción cultural para la libertad. Buenos Aires: Tierra Nueva. 
Freire, P. (1975b). ¿Extensión o comunicación? La concientización en el mundo rural. Buenos Aires: Siglo XXI.

Freire, P. (1975c). Las iglesias, la educación y el proceso de liberación humana en la historia. Buenos Aires: La Aurora.

Freire, P. (1990). La naturaleza política de la educación. Cultura, poder y liberación. Barcelona: Paidós.

Freire, P. (1992). Pedagogía del oprimido. Madrid: Siglo XXI.

Freire, P. y Faundez, A. (2010). Por una pedagogía de la pregunta. Valencia: Ediciones del CREC.

García Gómez, T. (2004). El turno de la educación dominada. Revista de Cultura, Asociacionismo y Movimientos Sociales, 3, 7-9.

García Gómez, T. (2011). La educación democrática: Proyecto comunal de ciudadanía. Revista Interuniversitaria de Formación del Profesorado, 14(2), 57-69.

Gimeno, J. (2005). Propuesta de directrices para el desarrollo del currículum basado en el derecho a la educación. En J. Gimeno, La educación que aún es posible (pp. 123-142). Madrid: Morata.

Giroux, H. (1990). Los profesores como intelectuales. Barcelona: Paidós.

Goodman, J. (2008). Educación para una democracia crítica. En F. Angulo (Ed.), Educación, justicia y democracia en las instituciones educativas (pp. 109-142). Sevilla: Cooperación Educativa.

Graciano, A. (2013). Los derechos humanos de tercera y cuarta generación. Recuperado de http://www.encuentrojuridico.com/2013/01/los-derechos-humanos-de-tercera-y.html

Guarro, A. (2002a). Reconstruir la escuela. Cuadernos de Pedagogía, 317, 57-60.

Guarro, A. (2002b). Currículum y democracia. Barcelona: Octaedro.

Guarro, A. (2005). La transformación democrática de la cultura escolar: una respuesta justa a las necesidades del alumnado de zonas desfavorecidas. Profesorado. Revista de Currículum y Formación de Profesorado, 9(9), 1-48.

Imbernón, F. (2013). 10 ideas clave. La formación permanente del profesorado. Barcelona: Graó.

Jares, X. (2002). Educación y derechos humanos. Estrategias didácticas y organizativas. Madrid: Editorial Popular.

Kincheloe, J. (2008). La pedagogía crítica en el siglo XXI: Evolucionar para sobrevivir. En P. Mclaren y J. Kincheloe (Eds.), Pedagogía crítica (pp. 26-69). Barcelona: Graó.

Kramer, A. (2010). Derechos humanos: ¿̨quién decide? Madrid: Morata.

López Pacheco, J. (1992). Asilo poético. Madrid: Endymion.

Lukes, S. (2007). El poder. Un enfoque radical. Madrid: Siglo XXI.

Malgesini, G. y Giménez, C. (2000). Guía de conceptos sobre migraciones, racismo e interculturalidad. Madrid: Los Libros de la Catarata.

Miyares, A. (2003). Democracia feminista. Madrid: Cátedra.

Moreno, A. (1986). El arquetipo viril protagonista de la historia. Ejercicios de lectura no-androcéntrica. Barcelona: La Sal.

Pérez Gómez, A. (2012). Educarse en la era digital. Madrid: Morata.

Rogero, J. (2010). Escuela del cuidado mutuo. Aula de Innovación Educativa, 191, 59-62. 
Santos Guerra, M. A. (1995). Democracia escolar o el problema de la nieve frita. En Fundación Paideia. (Ed.), Volver a pensar la educación. Política, educación y sociedad (pp. 128-141). Madrid: Morata.

Santos Guerra, M. A. (2000). La escuela que aprende. Madrid: Morata.

Santos Guerra, M. A. (2003). La participación es un árbol. En J. Gómez García y F. Luengo (Coords.), Escuelas y familias democráticas (pp. 10-28). Madrid: Proyecto Atlántida.

Santos Guerra, M. A. (2013). Decálogo sobre participación. Recuperado de https://drive.google.com/file/d/oBoREJ_psIMnUWnpwdzNqck1TYUE/view

Spinoza, B. (1986). Tratado teológico-político. Madrid: Alianza Editorial.

Torres Santomé, J. (1994). Globalización e interdisciplinariedad: El currículum integrado. Madrid: Morata.

Torres Santomé, J. (2011). La justicia curricular. El caballo de Troya de la cultura escolar. Madrid: Morata.

\section{Breve CV de la autora}

\section{Teresa García Gómez}

Doctora en Pedagogía. Profesora Titular del área de Didáctica y Organización Escolar en la Universidad de Almería. Desde 1994 viene participando en distintos proyectos de investigación $\mathrm{I}+\mathrm{D}+\mathrm{i}$ y de Excelencia. Sus líneas de investigación son: coeducación, relaciones de poder, educación y género, alternativas pedagógicas, educación democrática e innovación educativa, participación democrática y educación para la ciudadanía. Entre sus últimas publicaciones destacan: "Francesco Tonucci (Frato): La maquinaria escolar"; "De la autoevaluación a la coevaluación”; "Maestras, amor y carreras profesionales”; “Qué ciudadanía enseñan los libros de texto?”; “Aportaciones ciudadanas desde el aprendizaje servicio. Universidad, escuela y comunidad conectadas"; "Rompiendo muros. La educación democrática: proyecto comunal de ciudadanía" y la edición de "Paulo Freire: Pedagogía liberadora", publicada en la editorial Los Libros de la Catarata. ORCID ID: 0000-00030251-2432. Email: tgarcia@ual.es 